She was lost sight of till Feb. 2, 1897. She now reports herself as being in good health, weighing fifteen pounds more than last May. During the past summer she twice noticed small amounts of blood in the sputum, not at times of period; probably accidental. Physical examination at this date is again. aside from the enlarged glands, which have changed but little, entirely negative. Menstruation has been regular.

The following points seem worth noting:

1. The patient has had periodic hemorrhage from the lungs for a long time, at least nine times within a period of fifteen months, without having, up to the present date, any demonstrable signs of lung disease.

2. In view of the fact that so many such cases are later seen to be tuberculous, prognosis was guarded, the more so on account of the enlarged glands. ${ }^{5}$ The fact that the patient has to all appearance recovered does not make it impossible that she may still have a healed tuberculous lesion in her lungs.

239 E. Town Street.

\section{PRIMARY SARCOMA OF THE IRIS.}

A STATISTICAL STUDY, WITH THE REPORT OF AN ADDITIONAL CASE IN WHICH THE GROWTH WAS SUCCESSFULLY REMOVED BY IRIDECTOMY.

Presented in the Section on Ophthalmology, at the Forty-eighth Annual Meeting of the American Medical Association, held at Philadelphia, Pa., June 1-4, 1897.

BY CLARENCE A. VEASEY, A.M., M.D. PHILADELPHIA, PA.

Primary sarcoma of the iris is an affection so seldom met with that a report of each isolated case requires no apology. The following notes are from a very interesting case, kindly referred to $m e$ by $D r$. Joseph J. Burke, from whom the growth was succesfully removed by a broad peripheral iridectomy.

M. B., aged 46 years, a male, had been suffering from an inflamed left eye for three weeks when I was first asked to see him at his home. There was excruciating pain in the bulb that extended backward through the temporal region to the left side of the head, accompanied by intense photophobia on the least exposure to light, which was attributed by the patient to an attack of neuralgia. An examination, however, revealed marked pericorneal injection, a discolored iris, a contracted pupil with numerous posterior synechiæ and what appeared to be a brownish growth in the upper inner quadrant of the iris. Hot compresses at frequent intervals followed by the instillation of a solution of sulphate of atropin was the treatment prescribed and the patient was told to report at my office on the following day for further examination. Upon this occasion his vision was found to be for O. D. 5-9 and for O. S. 5-27, the latter eye being under the influence of a mydriatic and the patient complaining of everything looking very foggy. The vision of the left eye was unimproved by glasses. An examination of the right eye showed it to be normal with the exception of a low refractive error, which, when corrected, gave him perfect visual acuity.

An examination of the left eye showed an evenly dilated pupil except up and in. In this portion there were no synechiæ, but a small brownish tumor of the iris, somewhat ovoidal in shape, could be seen, the lower end of which was pushing the posterior pig-

5 We wished to remove one of these for purposes of diegnosis, but were not allowed. ment layer of the iris downward and backward giving to the pupil the shape seen in Fig. 1. With the red reflex from the fundus as a background the position of the lower end of the growth could be distinctly observed in the pupillary space. The growth itself was not so long as the entire width of the iris, as some iris tissue seemed unaffected both on the ciliary and pupillary ends, as well as upon the sides. It had the appearance of a foreign body making a bed, as it were, in the stroma of the iris, yet entirely separated from it and pushing the pigment layer before it as it grew backward. No blood vessels could be detected passing over its surface nor could any hemorrhages be seen. The capsule of the lens was somewhat cloudy and there remained a ring of pigment spots where the iris had been attached. No family history of tumors of any kind or specifio personal history could be elicited. The patient had had some necrosis of one of the bones of the leg many years before, which had been entirely cured. He has three healthy living children.

Upon examining a photograph of the patient taken eight years before, there was a suspicious looking shadow on that portion of the iris occupied by the growth that looked as if it might have been a dark spot. A history of two other attacks of "neuralgia," evidently iritis, during this period affords additional evidence that the growth had existed for some time, though unnoticed by any of the patient's friends or members of his family. For three weeks before my examination it had been increasing rapidly in size and there was present a severe plastic iritis.

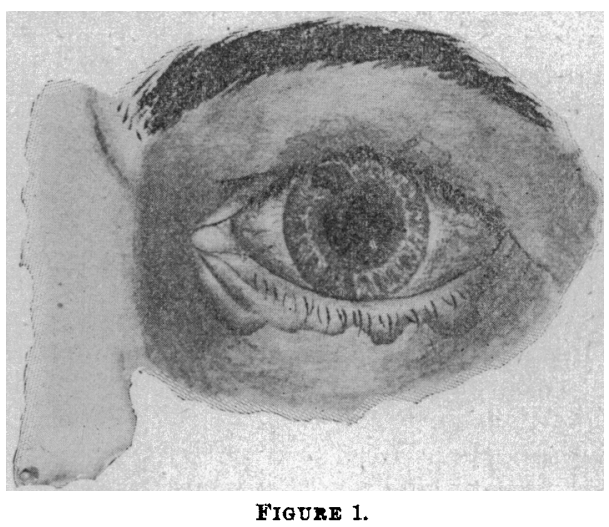

Upon consultation with Dr. George E. de Schweinitz he agreed with me that the growth was probably a primary sarcoma of the iris, but to give the patient the benefit of the doubt it was thought proper to administer mercurial inunctions and rapidly increasing doses of potassium iodid for a short time to see what effect might be obtained. These remedies were faith. fully employed for one week. at expiration of which time the growth was nearly twice as large as when first seen and the iritis was fully as bad, the pain still being intense, while the lens as well as the capsule was undoubtedly becoming opaque through the backward pressure of the lower, or pupillary end.

The growth was excised with a broad peripheral iridectomy without complication, except a profuse hemorrhage as soon as the inflamed iris was cut, a bent keratome and ordinary iris forceps being employed, there being no difficulty in drawing it out with the portion of the iris in which it was embedded. A small tag of the iris caught between the lips of the wound giving some pain for a moment, but as soon as it was released the pain disappeared. The eye made. 
an uneventful recovery notwithstanding iritis was present at the time of operation. The opacity of the lens continued to increase until vision was reduced to light perception, when, though much olear lens substance was present, it was extracted through a three millimeter corneal flap without complication. This was about eight months after the first operation. Though the vision in the left eye, before the growth was removed by the iridectomy, equaled only 5-27, after the extraction of the opaque lens with the correcting glass vision equaled $5-6$ and Jaeger 1 was easily read. So far as can be seen there has been no recurrence of the disease, fourteen months having elapsed since the growth was removed.

The tumor was somewhat crescentic in shape, being markedly concave on its inner surface and convex on its outer surface, measuring 2.5 millimeters in length, 1.5 millimeters in breadth and 1.5 millimeters in thickness. It was hardened in Müller's fluid and several sections were submitted to my friend, Dr. H. F. Harris of the pathologic laboratory of the Jefferson Medical College, who kindly furnished me with the following description of the growth and superintended the drawings, which were made by Miss Elizabeth Hard-

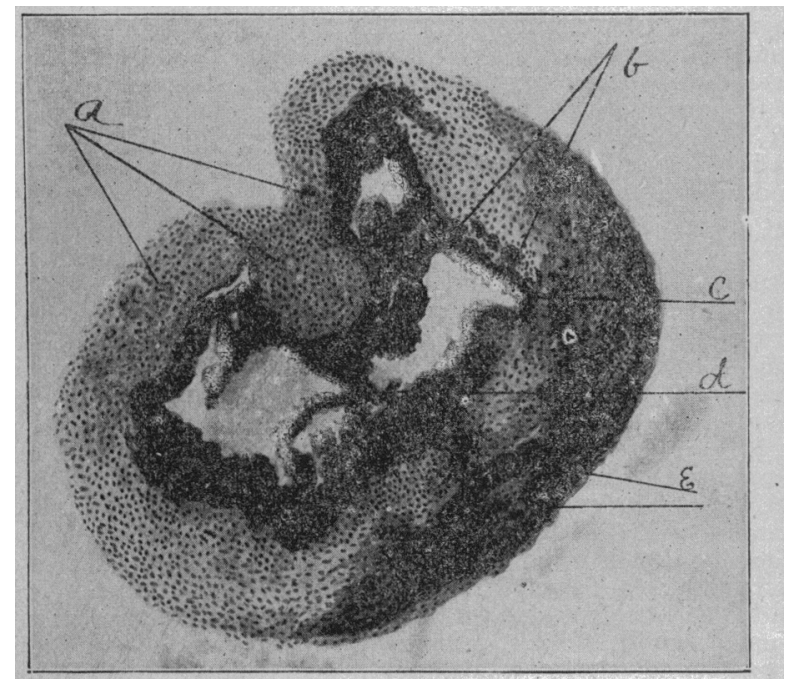

Figure 2.

ing: "Four sections of the tumor were submitted to me for microscopic examination. In general outline and size they are practically identical; in form they are somewhat kidney-shaped. In the center of each is a U-shaped open space (Fig. 2), the convex border of which corresponds with the convex border of the mass. Bounding this opening and forming the inner layer of the tumor is a continuous layer of dark pigment plainly discernible with the unaided eye. The sections of the tumor given to me are thus seen to consist of an irregular but continuous ring surrounding an irregular opening. The convex portion of this ring is more than double the thickness of the concave portion. The portion where the iris was attached is not seen in any of the preparations. This fact and the peculiar shape of the section can only be explained bp the supposition that the tumor had grown forward forming a hollow somewhat hemispheric mass, the concave surface of which was lined by the pigment layer of the iris, and that segments of this mass were cut anterior to its attachments. One of the sections was stained with hematoxylin and eosin, and the others with carmin. Under a low power the tumor was seen to consist of small round cells with a considerable amount of intercellular substance. Numerous blood vessels were seen scattered through the growth. These vessels were especially numerous in the tissue forming the thin concave portion of the ring, and were remarkable for the thickness of their walls and for the fact that they contained no blood. The vessels of the thicker portions were filled with blood, and so far as could be seen had no walls, the blood being apparently in direct contact with the cells of the tumor. Numerous dark brown pigment granules were seen scattered through the tissues of the thicker portions of the ring. This was especially marked around the outer border. The pigment layer surrounding the inner border of the tumor was dark brown, almost black in color, and while continuous, was very irregularly disposed over the surface, several bands projecting into the open space in the center of the mass.

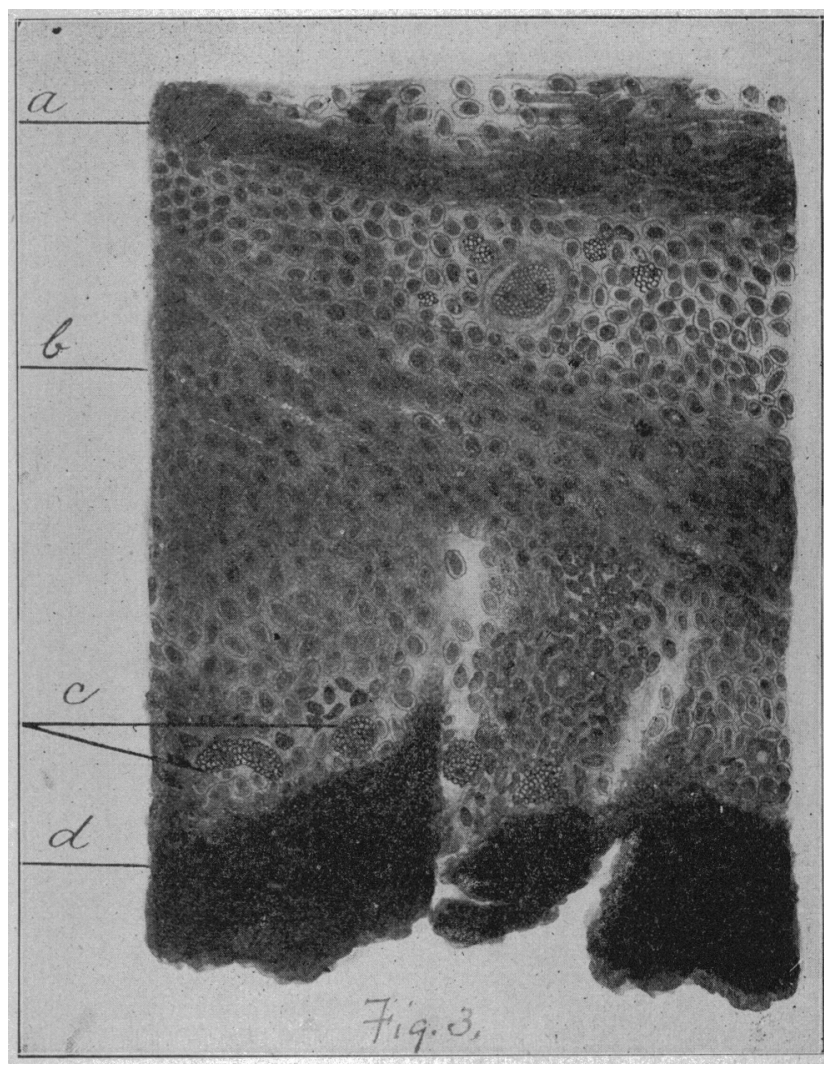

FIGURE 3.

"When examined with higher powers the cells which compose the greater part of the tumor were seen to be small round cells with which were intermingled a few oval ones (Fig. 3). These cells were almost of uniform size, having a diameter of from 10 to 12 microns. Their nuclei were stained of an almost solid color both in the hematoxylin and carmin preparations, in no case being sufficiently well preserved or stained to show the finer details. The nuclei were surrounded by a thin rim of protoplasm in which there were often em. bedded multiples of small pigment growths. In many situations, notably about the center of the thicker portions of the tumor, there is a considerable amount of firmly granular intercellular substance. In several places distinct bands of fibrous tissue and minute bundles of involuntary muscular fibers can be distinguished. Most prominent along its convex border, 
but scattered throughout the tumor, are numerous masses of granular dark brown pigment, varying in size from immeasurably small particles to collections having a diameter considerably greater than that of the cells which compose the tumor. From the pigment layer which covers the inner surface of the tumor numerous fine spiculæ of pigment substance are seen projecting between the neighboring cells. The tumor is, however, much less pigmented here than along the outer border and as has been before mentioned, much of this pigment is found within the protoplasm of the cells. The inner pigment layer presents the characteristic appearance of the pigment layer of the iris. The tumor is I think beyond doubt a pigmented, small round-cell sarcoma."

During the past twenty years several analyses of the previously recorded cases of sarcoma of the iris have been published, the most extensive, however, being those of Fuchs, Andrews and Werther. In 1882 the former published his classic treatise, "Das Sarcom des Uveal Tractus," in which he analyzed sixteen cases that he had collected from the literature up to that time. In a recent number of the Archiv für Augenheilkunde, F. Werther adds to Fuchs's list twenty-three cases collected from the literature appearing between 1882 and 1893 . These tables have to a considerable extent evidently been compiled from incomplete abstracts of the original reports, as many of the important details of some of the cases have been omitted in the former but are found in the latter. In addition some of the cases have been found to be incorrectly classed; for example, when a non-pigmented sarcoma is placed under the heading "melanotic," and some of the cases were never operated on and are therefore useless for statistical purposes.

In the following list a few cases recorded prior to 1893 that seemed to have been overlooked in the previous papers, as well as those that have been reported from that date to the time of writing this paper (Feb. ruary, 1897), have been added. No case in which the growth was not operated on, and hence no histulogic examination made has been included. Briefly, the principal points in the history of each case are as follows:

Case 1.-Adams. A female, 13 years of age, was brought to the author with a small brown tumor about twice as large as a pin's head situated on the lower and outer part of the left iris. While treating with mercury the size increased and another mass appeared in the neighborhood of the first. Vision equaled $20 \%$. Several opaque spots were observed in the deeper layers of the cornea. Enucleation was performed and the grow th was found to be a round-celled sarcoma.

Case 2. - Alt. This case was a female 2 years of age. One month before the examination a small grow th had been noticed on the right iris. The lens was cataractous. Tension at first was normal but later became elevated. There were several nodules throughout the iris, the largest being in the lower and outer quadrant. Enucleation was performed and the growth, which originated in the parenchymatous tissue of the iris, was a round-celled sarcoma.

Case 3.-Andrews. The patient, a female 47 years of age, had noticed discoloration of the left iris at the site of the growth for many years. The vision of this eye had been periodically obscured for fifteen months. There was no pain and the vision of each eye equeled $2 \%$. Iridectomy was performed and was followed by suppuration of the globe requiring enucleation a week later. Microscopic examination showed that the entire growth had been removed by the iridectomy. There had been no recurrence eight years later.

Case 4.-Andrews. This patient was a female, aged 43 years. A small growth on the left iris had been observed for a long time. The tension was elevated but the vision equaled $2 \% / 20$. There was some circum corneal injection but no pain. Enucle. ation was performed and the growth proved to be a pigmented spindle celled sarcoma originating in the stroma of the iris.
The canal of Schlemm was somewhat narrowed and surrounded by a collection of the spindle-shaped cells.

Case 5. - Buffum. A female, aged 55 years, had noticed a "peculiar appearance" of the right iris for eight years. She had become blind in this eye gradually after repeated attacks of inflammation. The last attack was present three weeks before the examination. Since then the pain had continued. There was an injected bulb and the tension was about +2 . In the upper part of the iris there was a cyst-like development involving the upper two-thirds. The lower third contained several brownish spots. The aqueous was muddy, the lens hazy and the fundus indistinguishable. The growth was removed by iridectomy. Recurrence took place in three monthe. Enucleation was then performed. No recurrence had taken place at the expiration of eighteen months. The tumor was a spindle-celled sarcoma. The ciliary body had become secondarily involved.

Case 6.-Carter. The patient was a male, age 15 years, who had noticed s6veral small specks on the left iris for three months, and two small specks on the right iris for fourteen days. At the time of the examination there was a yellowish growth half as large as a pea in the lower and inner quadrant of the left iris and small yellowish spots at the margin of the right iris in the external half. There were small circular opaque deposits in the layers of the cornea. The tension was normal and Jaeger 1 could be read with each eye. Iridectomy was performed in the left eye but the growth recurred. In the right eye the spots were so enlarged nine months after the operation that only large objects could be seen. The tumor was a roundcelled sarcoma.

Case 7.-Charnley. This patient was a male, aged 16 years. A spot had been observed on the iris eleven years before and there had been occasional attacks of obscuration of vision from hemorrhage into the anterior chamber. At the time of the examination there was found on the lower and inner quadrant of the iris a small brownish-gray tumor about one-twentieth of an inch in diameter. Vision equaled \%. Recently red spots had appeared on its surface. It was removed by iridectomy and proved to be a non-pigmented spindle celled sarcoma.

Case 8.-Collins. A male, aged 21 years, presented himself for the treatment of a brownish growth of the left iris that was situated on the inner and lower quadrant. A photograph of the patient taken four years before the examination showed a brown spot on the lower and outer portion of the iris. At the time of the operation, however, the larger portion of the growth was on the lower and inner quadrant of the iris. Vision equaled $\%$ and the tension was "full." Enucleation was performed and the growth, which was a pigmented, small round.celled sarcoma, had not recurred in seventeen months.

Case 9.--Dreschfeld. A female, aged 53 years, had noticed some trouble with the left iris for two and one-half years. Examination showed a reddish grey tumor about the size of a split pea in the lower part of the iris. The eye was enucleated and the growth, which probably originated from the intermus. cular tissue of the iris, was a non-pigmented spindle celled sarcoma. The patient was under observation for several years, there having been no recurrence when last seen.

Case 10.-Edsall. A female, aged 23 years, had observed a small growth on the temporal side of the left iris, midway between the peripheral and pupillary margins about two years before. At the time of the examination the growth was about the size of a split pea covering the pupillary space and of a dark gray color with a smooth surface. The tension was elevated and the vision equaled $2 \%, 30$ through a small hole in the center of the growth. Frequent hemorrhages were observed in the anterior chamber. Although the personal and family histories were negative, mercury and potassium iodid were administered for a time but without any beneficial result. Enucleation was then performed and the growth was a pigmented, small spindlecelled sarcoma.

Case 11.-Ewetzky. This patient, a male, aged 38 years, had noticed some trouble with his left eye for two weeks. Examination revealed a growth in the posterior part of the upper half of the iris pushing the iris forward and pressing on the lens. The tension was normal at this time but later became elevated. Vision equaled $1 \% \%_{0}$. As there was a history of syphilis acquired fifteen years before, the patient was treated with mercury, but vision became reduced to the counting of fingers. Enucleation was then performed and the growth proved to be a pigmented round-celled sarcoma.

Case 12.-Fano. The patient was a male, aged 19 years, who had a small brownish growth partially filling the anterior chamber of the left eye. There was same injection of the eyeball and slight vascularization of the cornea with hypopyon Light could not be distinguished. The cornea was perforated. The operation for staphyloma was first performed and a week 
later the stump was enucleated. The examination showed small, regular, pigmented cells.

Case 13.- Hirschberg. The patient was a man aged 38 years, who had noticed a dark spot on the iris of the right eye since childhood, but which had been increasing in size for one year. The visual acuity equaled $2 \%$ and the tension was normal. At the time of the operation there was a brownish growth occupying the lower two thirds of the anterior chamber that had originated in the lower portion of the iris. Enucleation was performed, and microscopically the growth was a pigmented spindle-celled sarcoma, probably originating from the anterior layers of the iris. There was no recurrence in six monthis.

Case 14. Hosch. A male, aged 66 years, had observed a brown spot on his right iris since youth. There was some injection in the lower part of the conjunctiva but no pain. The lower part of the anterior chamber was filled with a light brown growth that was pushing the iris slightly backward, and that extended almost to the center of the pupil. Externally the margin of the tumor was well defined; internally it disappeared into the iris stroma so that no line of demarcation could be made out macroscopically. The tension was normal and the vision, which at first equaled 18/30 with a Hm. of 2D., at the time of the operation equaled $16 / 100$. The bulb was enucleated and the growth, which was 4 millimeters thick and 7 millimeters high, was confined to the iris and microscopically proved to be a pigmented spindle-celled sarcoma.

Case 15.-Kipp. A male, aged 36 years, had noticed a spot on the right iris twelve years before. For one month it had been growing very rapidly. At the time of the operation there was a whitieh growth that covered a large portion of the pupil. Tension was normal and vision equaled $2 \%$. The growth began in the lower and inner quadrant of the iris. It was excised by iridectomy and proved to be a non-pigmented spindlecelled sarcoma that probably originated in the iris stroma. There was no recurrence in eighteen months.

Case 16.--Knapp. A male, aged 36 years, had a growth occupying about onethird of the iris, which was whitish and obstructed the entire pupil when the latter was not dilated. Vision equaled $2 \% 0$. Iridectomy was performed and there had been no recurrence of the growth at the expiration of a year. The latter was a non-pigmented spindle-celled sarcoma originating in the iris stroma without any definite line of demarcation.

Case 17. - Knapp. A female, aged 35 years, had a blackish growth about as large as a pea, situated in the lower part of the iris that had been present for many years. During the four years preceding the examination there had been attacks of iritis and temporary increase of intra ocular tension. At the time of the examination, however, the tension was normal and the visual acuity equaled $2 \% 100$. There was some lenticular opacity that was supposed to have been congenital. An iridectomy was performed and the tumor, which proved to be a pigmented spindle celled sarcoma, grew from the iris stroma without any definite line of demarcation. There were two mild attacks of iritis after the operation, but no recurrence of the growth had taken place in three years.

Case 18. -Knapp, A male, aged 22 years, had observed a small speck in his left iris ten years before. Examination showed a yellowish red growth extending from the iris into the anterior chamber, originating in the lower and outer quadrant and studded with red dots and lines. The tension was normal, although temporarily elevated at times, and the vision was $2 \%$. The growth was removed by an iridectomy and proved to be a non-pigmented round-celled sarcoma originating from the iris stroma without any definite boundary line.

Case 19.- Knapp. A female, aged 53 years, had observed a tumor of the upper and outer quadrant of the iris four months before the examination that had been rapidly increasing in size. It was rather reddish and about the size of a cherry stone. The tension was normal and the vision equaled the perception of light. The eye was enucleated and the tumor, a round-celled sarcoma, was found to have originated from the root of the iris near the ciliary processes.

Case 20.-Krükow. A woman, 25 years old, had noticed for more than seven years a small black spot in the upper and outer quadrant of the right iris. The growth filled about one-fourth of the anterior chamber, covered half of the pupillary space and reached to the cornea. There had been some hemorrhages into the anterior chamber but these were always absorbed. Vision equaled $1 \% / 30$ (myopia $1 / 3 \beta$ ). The tension was normal. Iridectomy was performed for the removal of the growth which was a pigmented sarcoma consisting of spindle and round cells. There was no recurrence in one year.

Case 21.--Lebrun. A female, aged 36 years, had noticed failing vision for three months, during which time some brown- ish spots about the size of a radish seed were observed near the external periphery of the iris. The eye was blind. After treating for a while with negative results an iridectomy was performed. Inflammatory symptoms were so great, however, that two weeks later enucleation was performed. The growth was pigmented mixed, round and spindle-celled sarcoma.

Case 22.-Limbourg. This patient was a female, seven and one half years of age, whose vision in the left eye had been much reduced for fourteen days. There was slight episcleral injection and some fine lymph exudate was observed on the posterior surface of the cornea. The anterior chamber appeared to be deeper than normal. The upper and inner part of the iris was occupied by a small yellowish growth, with a smooth surface that reached to the cornea in front. The tension was elevated and vision equaled the counting of fingers at $1 \mathrm{M}$. The eyeball was enucleated and the growth proved to be a nonpigmented round-celled sarcoma. The ciliary body and canal of Schlemm had become secondarily involved.

Case 23.- Little. The patient, a female, aged 20 years, gave the history of sudden blindness in the right eye sixteen months before while stooping. This lasted for about one week. On recovering her vision she noticed for the first time a spot on the colored part of the eye. During those sixteen months there had been three or four attacks of dimness of vision at irregular intervals, but after each attack vision had returned. These were presumed to be due to hemorrhage into the anterior chamber. At the time of examination there was a pale brown mass about the size of a small pea in the lower and outer quadrant of the iris that extended from the pupillary margin to the periphery. Vision equaled 2\%. The growth was removed by an iridectomy and was found to be a pigmented roundcelled sarcoma. There had been no recurrence in twenty-one months.

Case 24.-Oemisch. A female, aged 42 years, had observed six years before a dark spot on the lower and inner quadrant of the iris, from which there were occasionally hemorrhages. During these periods the vision was markedly reduced. After a period of quiescence it began to grow rapidly. In the anterior chamber there was a dark grayish-blue mass that reached nearly to the surface of the cornea and covered a large part of the lower and inner quadrant of the iris. It was about as large as a pea and reached to the pupillary margin. Iritis had been present. Vision equaled 5\%. The growth was removed by iridectomy and was a non-pigmented spindle-celled sarcoma. There was no recurrence in four months and the patient had useful vision, being able to read "calendar figures" at $6 \mathrm{M}$.

Case 25.-Pflüger. The patient was a female, aged 55 years, who had observed a growth on the right iris six years before. It had been gradually increasing in size and there was entire absence of pain. There was a history of malignant disease in the mother originating in the naso-orbital region and extending to the globe of the eye. In the present case the cornea was normal. In the lower outer quadrant of the iris there was a dark brown tumor of irregular contour about 3 by 4 by $5 \mathrm{~mm}$. in size, extending from the periphery of the iris almost to the pupillary margin. A bove the horizontal meridian there was a second smaller growth, separated from the other near the pupil by healthy iris tissue, but connected with it near the periphery of the iris. The pupil was round, but with mydriasis there seemed to be posterior synechiæ and opacity of the lens and capsule. Vision equaled 5/15 in each eye. $\tilde{A}$ broad peripheral iridectomy was performed, removing both parts, and there had been no recurrence in two years. The visual acuity remained $5 / 15$. The growth was a pigmented spindle-celled sarcoma.

Case 26.-Pflüger. In the same paper the author records a case occurring in the practice of Dr. Horner, the history of which is as follows: A female, 36 years of age, had been aware for ten years of the existence of a small black spot on the lower quadrant of the left iris, that for a short period had been gradually increasing in size. The eyes were not inflamed. The pupil was oval and the growth extended from the margin of the pupil to the angle of the anterior chamber. It was removed by iridectomy and had not recurred at the expiration of three years. The microscopic examination is simply stated to have proved the diagnosis of sarcoma to have been correct.

Case 2\%.-Quaglino and Guiato. The patient was a female child, aged 6 years, on whose left iris there had been observed a small growth three months before. There was no irritation nor severe pain. Tension equaled +2 , The patient could only count fingers, and the mass occupied about two-thirds of the anterior chamber. The parents were perfectly healthy. Enu. cleation was performed and was followed by a phlegmonous inflammation of the orbit. Microscopic examination showed the growth to be a pigmented round and spindle-celled sarcoma.

Case 28. - Robertson and Knapp. A fomale, aged 24 years, complained of poor vision in the right eye for one year. Exam- 


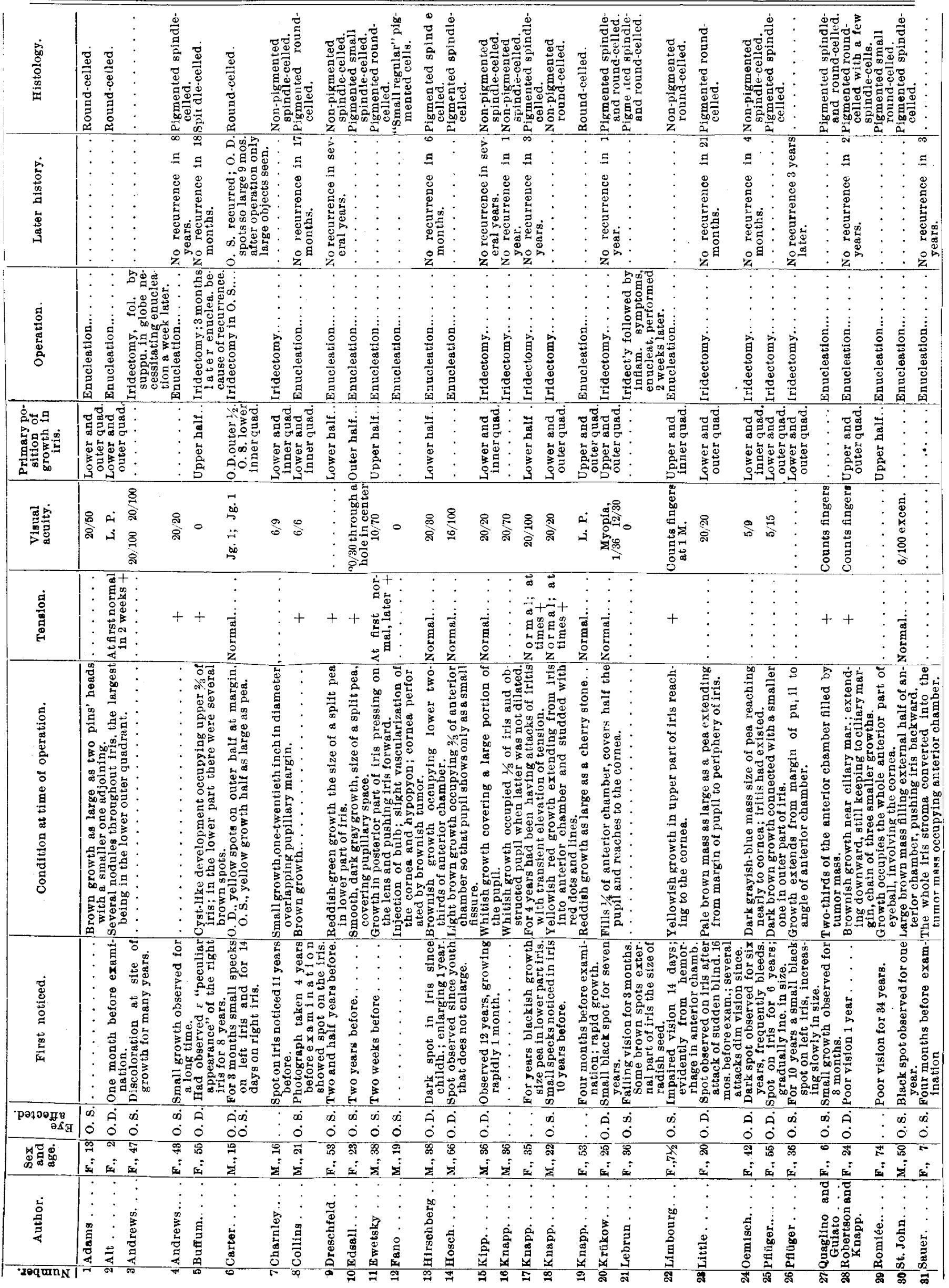


ination showed a brownish tumor in the upper and outer part of the iris at the ciliary margin, and extending downward from this a chain of three smaller grow ths still keeping to the ciliary margin. Vision equaled the counting of fingers and the tension was elevated. Enucleation was performed and microscopic examination showed the grow th to be a pigmented round-celled sarcoma with a few spindle-cells here and there. There had been no recurrence at the expiration of two years. The origin was supposed to have been from the anterior layers of the ciliary portion of the iris.

Case 29.--Romiee. This patient was a female, aged 74 years, who had not been very well since she was 40 years of age. Examination showed an irregular growth occupying the whole of the anterior portion of the bulb, the cornea being involved. Enucleation was performed and the growth was a pigmented, small, round celled sarcoma that had its origin in the upper half of the iris. The retina was found detached, but the lens, choroid and sclera were unaffected. The growth had pierced the cornea in the upper part.

Case 30.-St. John. A male, 50 years of age, had noticed a black spot on the left iris for one year. The tension was normal and the vision equaled $6 / 100$ eccentrically inward. There was a large brown mass filling the external half of the anterior chamber and pushing the iris backward. Pressure on the cornea in front had caused a "hazy spot." The bulb was enucleated and the growth was a pigmented spindle-celled sarcoma.

Case 31.-Sauer. The patient was a female, 7 years of age. Four months before, there had been observed a growth on the left iris that had been rapidly increasing in size. At the time of operation the whole stroma of the iris seemed to have been converted into a tumor mass that occupied the whole anterior chamber. Enucleation was performed and the growth was a mixed-celled sarcoma. consisting of round and spindle cells. No recurrence had taken place at the expiration of three years. Case 32.-Schiess. This case is a most interesting one. A $\therefore$ female, 55 years of age, had noticed a gradual failure of vision of the right eye for seven weeks. There were also temporary attacks of increased intra ocular tension. At the time of examination a tumor was found in the posterior chamber pushing the iris forward. There were also seven large and small brownish spots in the ciliary region of the sclera. The eye was not sensitive nor was there any pain or irritation. The bulb was enucleated and microscopic examination showed that the ciliary body contained a true melanoma, while the growth in the iris was a pigmented spindle-celled sarcoma. The latter was supposed to have been secondary to the first and originated in the upper and inner quadrant of the iris.

('ase 33.--Solomon. A female, 43 years of age, had noticed a small brownish speck about as large as a pin's head on the outer ciliary margin of the right iris twenty years before. It had been gradually increasing in size and growing toward the pupillary margin, which it overlapped at the time of the operation. The tension was normal and vision equaled $2 \% 1 \%$. The lens was clear but the vitreous cloudy. Enucleation was performed and the growth proved to be a pigmented round and spindle-celled sarcoma, some cells having passed in to the sclera, following the course of Schlemm's canal.

Case 34.-Tay. A male, aged 25 years, had observed a peculiar growth on the lower half of the left iris for ten years. There was a grayish jelly. like mass with opaque points scattered through it covering the pupil. The vision remained normal until the pupil was covered by the growth. The eye was enucleated and the microscopic description of the growth was that of a "medullary cancer with pigment," which in all probability was a sarcoma.

Case 35.-Thalberg. The patient was a female, aged 64 years. Following the extraction of cataract and looking very much like a secondary cataract, there developed in the anterior chamber filling the pupillary space and involving the iris a whitish growth. The cornea became somewhat thickened, the tension was increased and vision was totally destroyed. The growth looked so much like a secondary cataract that an opera. tion for the latter was performed. Pain persisted, however, and the growth increased in size so that enucleation was finally performed. The whole iris was found to have been involved by a non-pigmented sarcoma composed of large and small round, spindle and polygonal cells. The growth had its origin in the endothelial cells of the iris.

Case 36.-Verter. A female, 72 years of age, possessed a dark brown tumor of the right iris about the size of a hempseed, involving the peripheral portion of the iris and lying closely against the posterior surface of the cornea, occupying about one-third of the anterior chamber. There was present an over-ripe cataract and the eye was blind. There was no pain nor irritation, and the patient could give no account of the growth. The eyeball was enucleated and sections of the 
tumor showed it to be a pigmented spindle-celled sarcoma The ciliary body, the spaces of the pectinate ligament, the venous plexus and the equator of the lens were all secondarily involved.

Case 37.-Verter. This patient was a female, aged 60 years, who had observed some weeks before a small dark, cinnamoncolored growth upon the right iris. The media were transparent and the visual acuity equaled $\%$ with $+\mathrm{S} 1.50 \mathrm{D}$. The vision of the left eye was normal with $+\mathrm{S} 1.50 \mathrm{D}$. Iridectomy had been advised at the time of first observation of the growth, but at the time consent to the operation was obtained the size was so much increased that enucleation was performed. The tumor was a pigmented spindle-celled sarcoma, and had secondarily involved the ciliary body, Schlemm's canal, Fontana's space and the cornea. A small cyst was also found in the periphery of the retina.

Case 38.-Walker. Patient was a female, aged 59 years, who had a cataract extracted from the left eye three years before without iridectomy. For a time before the examination the vision had been failing in this eye. There was no pain or in flammatory symptoms, but inspection showed a pinkish growth filling the pupillary space and strongly resembling secondary cataract. Discission was performed without benefit, the iris being rotten and adherent to the capsule. Three weeks later the eye was enucleated and the mass found to be a small spindle celled sarcoma. Before enucleation the growth had extended to the cornea in front, obliterating the anterior cham ber and looking very much like a large dislocated lens.

Case 39. - Webster and Van Gieson. The patient was a female, aged 60 years. For four weeks she had seen a "purple mist" before the left eye. There was found a growth about the size of a small pea in the lower and outer quadrant of the iris. The tension was elevated and the vision equaled $2 \% \%$. There was also present anterior polar cataract and edema of the retina. Enucleation was performed and the growth was found to be a pigmented spindle-celled sarcoma.

Case 40.-Werther. A female, aged 72 years, had a brown ish-black semiglobular tumor about the size of a hemp-seed, in the lower and outer quadrant of the right iris. Enucleation was performed and the growth was found to be a pigmented spindle.celled sarcoma.

Case 41.-Werther, A female, aged 60 years, had observed a few weeks before a semiblobular, brownish-black tumor of the right iris about the size of a hemp-seed. There was a hypermetropia of $1.50 \mathrm{D}$, and the vision equaled $\%$. The grow th was situated in the lower and inner quadrant. The eyeball was removed by enucleation and the growth proved to be a spindle-celled sarcoma, part pigmented and part non-pig mented. There was also found a cyst formation in the periphery of the retina.

Case 42.-Whiting. The patient was a male, aged 49 years, who had observed a spot on the left iris since 10 years of age Several years before he had consulted Dr. Knapp, and at that time the eyeball became occasionally inflamed and there were hemorrhages into the anterior chamber. At the present examination there was a dark brown growth filling the entire lower inner quadrant of the anterior chamber, covering the inferior internal margin of the pupil, which was oblong. There were no synechiæ. The cornea was slightly hazy from contact at several points. Vision of the right eye equaled $2 \%$; of the left, $2 \%$. Nine years later the patient returned on account of severe ocular pain and inflammation of the eyeball, which was now totally blind. The tension was elevated. Enucleation was performed and the growth was a pigmented mixed-celled sar coma, the round cells predominating. The choroid had become secondarily involved and contained a true bony formation.

The case is exceedingly interesting, as the grow th was watched for a long time, being observed at ten years of age, remaining harmless for twenty-five years, slowly growing for thirteen years with occasional attacks of iritis and hemorrhages in to the anterior chamber for seven years there being no doubt as to its malignancy. The patient refused earlier operative interference. There had been no recurrence at the expiration of six months.

Case 43.-Wiegmann. The patient was a female, aged 42 years. At birth there was observed a dark tumor about 3 $\mathrm{mm}$. in diameter on the lower and outer quadrant of the iris, that had remained unchanged until seven months before the examination, when it began to enlarge. The tension was normal and vision equaled $5 \%$. Iridectomy was performed and was followed nine months later by the application of the galvanocautery to a dark spot in the wound. This was repeated in about two weeks. The tumor was a pigmented spindle-celled sarcoma and no recurrence had been noted at the expiration of one year.

Case 44.-Williamson. This patient was a female, 14 years of age. Six months before, there had been noticed on the lower and outer quadrant of the left iris a yellowish spot. At the time of the examination the growth reached to the pupillary margin, having begun in the periphery. An attempt was made to remove the tumor by an iridectomy, but this was followed, three days later, by enucleation of the eyeball as the growth was found to be firmly attached by deep adhesions. Microscopic examination showed it to be a non-pigmented spindle celled sarcoma.

Case 45.-Zellweger. A female, aged 75 years, had noticed a small spot on the right iris for a long time. During the six weeks preceding the examination it had been growing very rapidly. There had been no pain or inflammatory symptoms at any time. The examination showed a pale, pinkish, vascular growth in the lower part of the iris, and beginning cataract. The tension was normal and the vision equaled the counting of fingers at $21 \%$ M. The growth was removed by iridectomy and was a nonpigmented small spindle-celled sarcoma originating from the anterior layers of the iris. There was no recurrence in situ in six months, but as the patient had some loss of appetite the author questions whether a recurrence had taken place by metastasis. Of this there was no later proof.

Arlt refers to two cases from whom the growth was removed by iridectomy, and to a third case requiring enucleation of the eyeball. In neither were there any details of the histories, either prior or subsequent to the operations.

Fuchs, in the discussion of a paper, refers to a case of primary sarcoma of the iris for which the eyeball was enucleated, but the details of the history are too meager to be of any use.

Cases in which primary sarcoma of the iris was diagnosed but which were not operated upon, are recorded by Berthold, Fuchs, Galezowski, von Graefe, Hasner, Owen, Pflüger, Saltzmann, St. John Roosa and Stober.

In order that the cases may be more easily analyzed, and to facilitate reference to any particular point in connection with them the accompanying table has been prepared somewhat after the manner of Fuchs. It will be seen therefore from the above that there have been recorded forty-six cases of primary sarcomata of the iris in which operative procedures have been undertaken and microscopic examinations made. Of these cases we have fourteen males, thirty-two females, giving, in round numbers, 69.5 per cent. of females and 30.5 per cent. of males.

The ages range as follows: From 1 to 5 years, one case; from 6 to 15 years, six cases; from 16 to 25 years, nine cases; from 26 to 35 years, 1 case; from 36 to 45 years, ten cases; from 46 to 55 years, nine cases; from 56 to 65 years, five cases; 66 to i5 years, five cases.

By referring to the above it will be seen that between the ages of 15 and 25 inclusive there occurred ten cases, and between 35 and 45 inclusive there occurred eleven cases, whereas the intervening period, from 25 to 35 , contained only one case. There seem, therefore, to be two periods during which the disease is most likely to manifest itself, viz., between the ages of 15 and 25 and between the ages of 35 and 45 , with a very moderate increase of predisposition in favor of the latter period, the intervening period, that is from

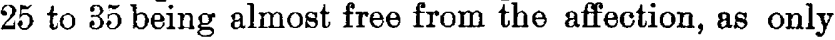

1 If instead of analyzing the ages according to decades, we take 5-year periods, the age of predisposition can be reduced even further, still conforming to from 16 to 20 to 10 three from, fears, no cases, from 31 to 35 years, one case, from 36 to 40 years, six cases 51 to 55 years, five cases; from 56 to 60 years, four cases ; from 61 to 65 ; from 51 to 05 years, ive cases; from 56 to 60 y ears, four cases; from 61 to 65 years, one case; from 66 to 70 years, one case; from 71 to 75 years, four cases It will be seen, therefore. according to this, that from 20 to 25 and from 35 to 40 years of age afford the periods of greatest predisposition. This perhaps, being slightly more accurate as it affords a greater range 
one of the forty-six cases occurred during this time. Beyond the age of $4 \tilde{5}$ the predisposition decreases very gradually and vice versa, the nearer we approach this age the greater becomes this predisposition.

It must be considered, however, that the above figures represent in many cases the ages at which the patients were operated upon. But as the greater number of cases were operated upon shortly after coming under the observation of the various authors, and as most of them came under observation shortly after the growths in the iris were discovered, the two periods given represent quite fairly the decades of greatest predisposition.

The youngest case in the list was 2 years of age and the oldest 75 years of age, the average age being 39.3 years.

It is to be noted also that seventeen of the cases occurred before the 35 th year and twenty-nine after the 35 th year; or, if the 40 th year be taken as the dividing line we have an equal number on either side, namely, twenty-three.

As to the ages when the growths were first observed to be in an active state, it is impossible to give any definite statistics. The larger number of patients consulted surgeons within a short time after the discovery of the affection, but it must be remembered that many of the growths have the history of originating from apparently dark tumors of the iris, melanomata, which after remaining in a state of quiesence for many years assumed a malignancy that microscopic examinations afterward proved to be sarcomata.

We find that the left eye has been more frequently affected, though the difference in predisposition is not marked, the actual ratio being as follows: Right eye affected in nineteen cases; left eye affected in twentyone cases; both eyes affected in one case; not stated in five cases.

The tension as given in the histories is as follows: Normal in eleven cases: elevated in sixteen cases; not stated in nineteen cases.

In five of the cases given as "elevated" the histories state that the tension was normal as a rule, but at times elevated. Thus of those cases in which the condition of the tension is recorded we have 40.7 per cent. normal, 40.7 per cent. elevated and 18.6 per cent. as varying, being sometimes normal and sometimes elevated. This differs somewhat from the recently published statistics of Devreaux Marshall, who has found in intra-ocular neoplasms affecting the iris or ciliary body that the tension is increased in 35.71 per cent. diminished in 14.28 per cent. and normal in 50 per cent. As his cases were not, however, exclusively primary growths of the iris, but growths affecting either the ciliary body or the iris, or both, being primary and secondary, the difference may be easily accounted for. In no one of the cases of primary sarcomata of the iris was the tension stated to have been diminished.

The condition of the visual acuity in these cases ranged thus: Normal in nine cases; 20/100, or better, in fourteen cases; less than $20 / 100$ in eight cases; light perception in two cases; blind in six cases; not stated in eight cases.

In some of the cases the lens was more or less cataractous (Alt's, Knapp's, Oemisch's, Verter's and my own). In the latter case, after the extraction of the lens the patient obtained vision equal to $5 / 6$ and easily read Jaeger 1.

The positions occupied by the tumors on the surfaces of the irides are variously given as follows: Lower and inner quadrant, seven cases; lower and outer quadrant, eleven cases; upper and inner quadrant, three cases: upper and outer quadrant, three cases; lower half, five cases; upper half, three cases; outer half, two cases; not stated, thirteen cases.

Of the thirty-two definitely stated cases we have, therefore, twenty-three cases, or 71.8 per cent. orignating from the lower half of the iris, and nine cases, or 28.2 per cent. originating from the upper half of the iris. There seems also to be a somewhat greater predisposition to occur in the outer portion of the lower half, or in the lower outer quadrant of the iris.

The operations that were performed in the recorded cases were: Enucleation in thirty-two cases; iridectomy in fourteen cases. In the above thirty-two cases under the heading "enucleation" are included four cases in which iridectomy was first performed and in which enucleation was subsequently required. In Andrews' case, enucleation was performed a week after the iridectomy, because of suppuration of the globe; in Lebrun's case it was performed two weeks later because of "inflammatory symptoms" in the globe; in Williamson's case three days later, because the iridectomy disclosed the fact that the growth was attached by "deep adhesions;" in Buffum's case three months later, because of recurrence. In Carter's case the growth recurred, but it was so distinctly unfavor. able that nothing else could have been expected. So that we have out of forty-six cases operated upon, the successful removal of the growth in thirteen cases, by iridectomies, in which no recurrence is recorded during the time they remained under observation, which varied from four months to many years. In none of the enucleations are recurrences positively recorded, but in one (Zellweger's case) a loss of appetite with some gastro-intestinal disturbance was looked upon as probably the beginning of a metastatic process, though no subsequent mention is made of it.

The histologic examinations of the growths showed that twenty-seven were pigmented, ten cases were non-pigmented, and nine cases not definitely stated.

It seems somewhat odd that in a tissue so highly pigmented as the iris we should have a non-pigmented growth, yet in the thirty-seven cases definitely recorded we have in round numbers 27 per cent. of the nonpigmented variety and 73 per cent. of the pigmented variety.

As to the cellular formation of the growths we have twenty-three cases of spindle celled; eleven cases of round celled; seven cases of mixed celled; five cases not definitely stated.

This, in round numbers, places in the spindle celled classification 56 per cent.; in the round celled classification 27 per cent, and in the mixed celled classification 17 per cent. of the reported cases.

Symptoms.-From a study of the recorded cases it is seen that primary sarcoma of the iris may occur at almost any age, the youngest being 2 years, the eldest 75 years of age, the periods of greatest predisposition being between the 15 th and the 25 th, and between the 35 th and the 45 th years. As a rule it is first observed as a spot of discoloration upon the iris, which, after a period of quiescence varying from a few weeks to many years, begins to increase rapidly in size, interfering with vision according to the degree of inflammation it has caused and the amount of pupillary space covered. Vision is also sometimes obscured for short periods of time by transient increase of the intraocular tengion or by hemorrhages from the growth 
into the anterior chamber. Sooner or later it is apt to produce iritis and by pressure backward to cause opacity of the capsule and lens. Tension is presumably increased when the growth attains sufficient size, or has brought about sufficiently violent inflammation to interfere with the interchange of the ocular fluids. If left to itself it attains considerable size, perforating the external coats of the eye, and usually produces blindness. It occurs twice as frequently in females as in males, each eye seems to be equally predisposed and the favorite position seems to be in the lower half, and especially in the lower and outer quadrant of the iris.

Diagnosis.-Primary sarcoma of the iris may be mistaken for simple melanoma, for gumma, or for primary tubercle of the iris.

A simple melanoma becomes darker and darker while a melano-sarcoma ordinarily retains its primary shade. A melanoma is also a congenital growth while sarcoma is not. . If the patient, or patient's family, can give no accurate information on this point the growth must be watched for some time to note if there is any progress (Fuchs).

Whenever a gumma of the iris appears there is a severe iritis, whereas in the early stage of sarcoma of the iris there are no inflammatory symptoms. In gumma of the iris, also, there is a specific bistory with other symptoms referable to syphilitic infection.

The color of the gumma is either an iron-red or deep yellowish-red, while that of sarcoma is reddishgray, blackish or light brown, or flesh-color (Andrews.) Gumma is non-vascular and yellowish-white in color at the summit, but at the base it is vascular and has a yellowish-red border(Fuchs). If the diagnosis can not be positively made from the examination, the administration of anti-syphilitic remedies, for a short time, in large doses will clear up the matter.

Tubercle of the iris is of much more rapid growth than sarcoma and in color is of a light yellowish-white, or light grayish-white, or light grayish yellow (Andrews). As a rule no vessels are seen on its surface, whereas in sarcoma superficial vascularization can usually be detected. The larger number of cases of tubercle have occurred in subjects under 15 years of age, whereas the larger number of cases of sarcoma have been found in older persons. Tubercle is much more irregular in form than sarcoma and the accompanying inflammatory symptoms also appear earlier.

Treatment.-If the growth is sufficiently amall and does not extend to the extreme ciliary portion of the iris an attempt should be made to remove it by an extremely broad peripheral iridectomy. The statistics conclusively prove that in many cases not only has the eyeball been preserved but with useful vision, and that no recurrence has been noted years after the removal of the growth by this operation. If the growth, however, is so large or is situated so near the ciliary margin of the iris that it is impossible to remove all of it by an iridectomy, or if any other portion of the eye has become secondarily involved, immediate enucleation should be performed.

BIBLIOGRAPHY.

1. Adams: On a Case of Sarcoma of the Iris and Ciliary Body, Lancet,

2. Alt: A Ca: of Sarcoma of the Iris in a Child Two Years Old, Amer. Jnur of Ophthal., 1890 , Vol. vii.

3. Andrews: Primary Sarcoma of the Iris, New York Med. Jour., 1889, p. 595 .

4. Andrews: Primary Sarcoma of the Iris, Trans. Amer. Ophthal. Soc. Vol. vii, p. 533 .

5. Arlt: Handbuch der gesammten Augenheilkunde, Graefe-Saemisoh, Bd. iii, p. 420 .
6. Berthold: Ueber die pathologische anatomischen Veränderungen der Augen Medien und Häute bei intraocularen Tumoren, Archiv $f$ Ophthalmologie, Bd. xv, p. 159.

7. Butfum: Ocular Neoplasmis, Jour. of Ophthal., Otol. and Laryngol., 1 , 1, p. 35

Carter: Case of Sarcoma of Both Irides, Trans. London Clin. Sco. 1874, Vol. vii.

. Charnley Case of Sarcoma of the Iris Removed by Operation, The Ophthalmic Review, 18\%2, No. 3.

Collins: Primary Sarcoma of the Iris, Royal London Ophthal. Hosp. Reports, 1889 , Vol. xii, p. 273 .

11. Dreschfeld: On a Case of Sarcoma of the Iris, Lancet, Jan. 16, 1875, p.

Edsall : Primary Sarcoma of the Iris, Med. News (New York), Jan 23, 1897, T. 107 .

Ewetzky: Ueber Dissemination der Sarkome des Uvealtractus, A rchiv f. Ophthalmologie. 1896 , p. 170.

L'Oeil. L'Union Medicale, 1865 , No. 59 .

Fuchs: Das Sarcom des Uveal Tractus, Wien, 1882.

16. Fuchs: Melanoma iridis. Archiv. f. Augenheilk, Bd. xi, p. 435

uchs: Auz. d.k. k. Gessellsch. d. Aertze in Wien, 1887, p. 198 (Quoted in Muench. med. Wochenschrift, 1887 , No. 46, p, 905

Galezowski: Tumeur melanosarcomateuse de l'iris, Recueil d'Ophth almologie, 1879 , 'T. i, p. 729.

19. v. Graefe: Ein melanotische Geschwulst der Iris, Archiv f. Ophthalmologie, Bd.1, p. 414

20. v. Graefe: Tumoren der Iris, Archiv f. Ophthalmologie, Bd. vii, 2 , p. 36.

21. v. Graefe: Zusütze ueber intraocular Tumoren, Archiv f. Ophthalmologie, Bd. Xiv, 2, p. 103.

22. v. Hasner: Melano-Sarcoma iridis primarium circumscriptum, Prag. med. Wochenschrift 1882 (Nagel's Jahrosbericht der Ophthal-

mologie, f. 1883 , p. 418$\}$.
23. Hirschberg: Ein Fall von Sarcoma Iridis, Archiv f. Ophthalmologie, Bd. xiv, 3 , p. 285 .

24. Hosch: Primäres Sarcom der Iris, Centrabl. f. prakt. Augenhellk., 1881, p. 361

26. Kipp: A Case of Primary Sarcoma of the Iris, Cured by Excision of the Tumor, Archives of Ophthalmology, Vol.v, p. 34 .

26. Knapp: Three Cases of Successful Removal of Sarcoma of the Iris, Archives of Ophthalmology, Vol.viii. p. 82.

7. Knapp: Die Intraocularen Geschwulste, 1868, pp. 175 and 220.

napp: Sarcoma of the Iris, New York Acad. of Medicine, Section on Ophthalmology, meeting of Nov 21, 1887 (Abstract in Phila. Medi-

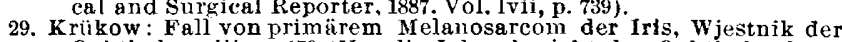
Ophthalm., iii, p. 179 (Nagel's Jahresbericht der Ophthalmologie

30. Le Brun: Tumeur sarcomoteuse de l'iris, extirpation du globe. Guerison, Annales d'Oculistique. T. Ix, 1869, p. 208.

imbourg: Ein Fall von Leucosarcom der Iris verbunden mit Iritis

Serosa, Archly f. Augenheilk. 1890, Bd. Xxi, p. 394.
33. Little: Case of Round-celled Sarcoma of the Iris; Successful Removal of the Tumor, Trans. of the Ophthalmolog. Soc. U. K., 1883, Vol. iii, p. 28 .

33. Marshall: Tension in Intraocular Tumors, Trans. of the Ohphthal. Soc. U. K., 1896.

35. Oemisch: Ueber das Sarkom der Regenbogenhaut, Inaug. Dissert.

35. Owen: Tumor of Iris, Brit. Med. Jour., Dec. 9, 1882, p. 1156.

36. Pflüger: Zur Kasuistik des Melanosarcoms der Augen, Universitäts augenklinik in Bern. Boricht ueber das Jahr 1883.

37. Quaglino Guiato: Contribuzione alla storia clinica ed anatomica dei tumori intra ed extra-oculari, Annali di Ottalmologia, vi, $2, \mathrm{~S}$. 163.

38. Robertson and Knapp: Sarcoma of the Iris, Archives of Ophthalmology, Vol. iii, 2,p 106 .

39. Romiec: Melanosareome de l'Iris: Recueil D'Ophtholmologie, April 1881, p. 207.

0. St. John Roosa: Vascular Tumor of Iris, Probably Sarcomatous, with Colored Plate, Trans. of the Amer. Ophthalmolog. Soc.. 1869, p. 14. Wiener Klinische Wochenschrift, 1893, No.9, p. 166.

42. Sauer: Beitrag zur Kasuistik der Irissarkome, Inaug. Dissert.,

43. Schiess: Zur Casuistic der Iris Tumoren, Archiv f. pathologische Anatomie und f. kliniscbe Medicin, 1876, Bd. Ixix, p. 100,

Amon : Melano-sarcomatous Tumor Growing from the Iris of the Right Eye, Trans. of the Ophthalmog. Soc. U. K., 1882, vol. ii, p. 257. d'Uculistique, 1853, T. xxx. p. 264 .

tho Primary Sarcoma of the Iris. Trans, of the Amer. Ophth. Soc., Vol, vii, 3. p 532.

ay: Primary Cancer of the Iris, Rosal London Ophthal. Hosp. Rp'ts.. 1866, Vol.v. p. 230 .

48. Thalberg: Zur pathologischen Anatomie des primären Irissarcoms, A rcbiv, f. Augenheilk., Bd. xiii, i, p. 20

49. Veasey: Concerning Primary Sarooma of the Irfs. A Statistical Study with the Report of an Additional Case in which the Growth was Successfully Removed by Iridectomy, Trans. Amer. Med. Assoc., Section on Ophthal., 1897.

60. Verter: Dva shichava sarkomi radiszhnoi obolocnki. (Two Cases of Sarcoma of the Iris). Vestnik Oftalmologit, Kiev, 1896, xili, Nos. 4 and 5 .

51. Walker: Sarcoma of the Iris, Trans. of the Ophthalmolog. Soc. U. K,

Vol. xv, p. 184 .
52. Webster and Van Gieson: A Case of Sarcoma of the Iris, Archives of Ophthalmol., 1889, Vol. xvifi, p. 15.

3. Wedl und Bock: Pathologische Anatomie des Auges, Wien, 1896.

4. Werther: Ueber das Sarcom der Iris, Archiv f. Augenhellk., 1896 , Bd. xxxii. 2, p. 297 .

55. Whiting: A Case of Primary Sarcoma of the Iris with Formation of Bone in the Subsequently Involved Chorold, Archives of Ophthalmol, 1890, Vol. xiv, 4

gmann : Ein Fall von Melanosarcom der Iris hervorgegangen aus einem gngeb. nærus: Ineul Dissert. Jene 1808.

Williamson: A Case of Spindle-celled Sarcoma of the Iris, Brit, Med. Jour.. Dec. 1893.

Augenheilk., 1888, Bd. Xxii, p. 366 . Discussion.

Dr. Howard F. Hansell of Philadelphia-My remarks on 
this interesting addition to the literature of primary sarcoma of the iris concern chiefly the differential diagnosis between this and other forms of tumor of the iris and ciliary body as I have had opportunity to observe them in my practice. These affec. tions, with the exception of tumors of syphilitic origin, are among the rarest of eye diseases and it is only by a collation of individual experiences rather than by the classic and oft. repeated dicta of any one writer that advance may be made in our knowledge. Until very recently I believe it was the common impression that sarcoma of the uveal tract was a distinctly fatal disease, but the paper of Mathews and the discussion that followed it showed conclusively that in many cases it was years before enucleation was necessary. The slowness of growth may be attributed to the serous sac that in cavities that have serous linings, forms over the tumor and prevents involvement and disintegration of neighboring structures. Eventually this envelope becomes attenuated to such a degree that it is no longer able to sustain the pressure from within and, rupturing, the sarcoma cells find new soil for development. Two cases exhibited this winter by Carpenter and Perrine, before the Section on Ophthalmology of the College of Physicians of Philadelphia, had been of extremely slow growth and enucleation was finally resorted to in order to relieve the pain of secondary glaucoma rather than because the tumors showed a tendency to spread. Identical grounds for treatment prevail when the tumor is recognized as belonging to the so-called benign variety, and we may therefore infer that primary sarcoma of the uveal tract is per se not an especially malignant affection.

The diseases that most closely resemble sarcoma of the iris are fibroma, cyst, gumma and primary tuberculosis ; yet in none of these should the diagnosis long remain uncertain, particularly after operative interference. Considered clinically only, a fibroma offers the following points of difference: It occurs as a rule in young patients as the result of traumatism, and is not a result of inflammatory exudation although it of ten gives rise to inflammation; the color is that of the iris stroma or darker; it is oblong in shape and shows a tendency to extend by increase in the area of ite base and not by layers of deposit; its surface is rough, presenting a strong contrast to the smooth encapsulated shining surface of the sarcoma. It is non-vascular except when the associated iritis is of high grade; exacerbations of iritis are common, hence posterior synechiæe, not limited to the site of the tumor although secondary to it, are numerous. Vision is interfered with according to the situation, size, rate of growth and the degree of transparency of the anterior capsule. Family history in the cases I have geen did not enter into a consideration of the diagnosis. In sarcoma there is perhaps a family history of tumor, the patients have reached middle age ; the outline is sharp and well defined, the surface is smooth and shiny to oblique illumination and its form round and, if old, nodulated; the pupil dilates irregularly, the non involved portion of the iris dilating to light and mydriatics while the portion adjacent to the tumor is adherent to the anterior capsule.

In cyst a history of traumatism can invariably be elicited; the tumor grows rapidly, soon coming into contact with the cornea anteriorly and dislocating the lens posteriorly; there is no iritis and but little interference with vision until adjoining parts are disturbed in their function; it is pearl color, non-vascular and painless, its outer limiting membrane is fibrous and its inner is serous in its nature; its contents is straw-colored, nearly transparent and semi-fluid. Thus in nearly every. essential it differs from sarcoma.

Gumma is always associated with and causatively related to the iritis of secondary or tertiary syphilis. In color, in intenaity of inflammation, in the presence of hypopyon or collections of broken-off necrosed masses of the tumor in the anterior chamber, in the severity and character of the pain, in the loss of vision and in the history, it offers few points of resemblance to sarcoma. In primary tuberculosis the iris is dotted in numerous places with small deposits, averaging the size of a pin's head, of somew hat lighter color than the healthy iris tissue. In the only case that has fallen under my observation it appeared in the early childhood of the offspring of a tuberculous parent. The vision was reduced to the perception of light, and there were no signs of inflammation.

One point of interest common to all cases of tumor either of the iris or other tissues of the eye, may be mentioned. I refer to the intra ocular tension. I have found tension to be unaltered until the late stages, when $I$ have regarded the increased pressure to be the result of secondary glaucoma and not to an increase in the contents or to a change in their character but to a disturbance of the relation between secretion and excretion. If perforation of the coats of the ball has taken place, high will naturally be succeeded by low tension and such a succession. would indicate an advance in the growth.

\section{A DUCTION INDICATOR AND PHORO. METER COMBINED.}

Presented to the Section on Ophthaimology at the Forty-eighth Annual Meeting of the American Medical Association, held at Philadelphia, Pa., June 1-4, 1897. BY A. E. PRINCE, M.D., PH.D.

SPRINGFIELD, ILL.

In 1892 I conceived the idea of simplifying the determination of the static relation of the optic axes by placing a Maddox rod behind two rotating prisms, thus avoiding the necessity of employing a series of prisms, and presented this conception in a paper read before the Ophthalmological Section of the AMERICAN Medical Association, at Detroit. In 1893 this idea was embodied in my phorometer published in the Archives of Ophthalmology. This conception has been adopted by Wilson in the construction of his instrument. The dial is so graduated as to indicate the combined effect of the two prisms in every possible relation to one another, and each quadrant of the dial is lettered to indicate the character of heterophoria. In testing for hyperphoria, the index will point to R.H., L.H., or 0, denoting the degree of right or left hyperphoria, or the existence of neither. Similarly in observations relative to esophoria or ex-

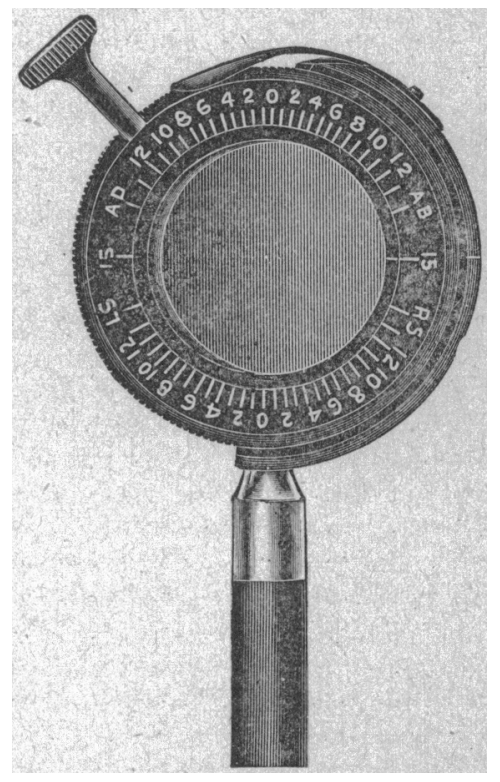

ophoria, the index will point to Ex., Es., or 0, denoting the degree of exophoria, esophoria or the absence of either of these conditions.

Prompted by the successful operation of this instrument in determining the static relation of the recti muscles, Bonschur \& Holmes in 1894 made, at my suggestion, an instrument for determining the dynamic capacity of the recti muscles. The prism employed had a strength of seven and a half degrees, thus furnishing every possible prism from 0 to 15 degrees. The graduated quadrants were lettered respectively Ad., Ab., R. S., and L.S., to indicate adduction, abduction, right sursumduction and left sursumduction. This instrument was presented to the profession through the Ophthalmic Record, July 1894, under the title of "A Duction Indicator and Developer."

The third step in the evolution is the use of a Maddox multiple red rod in place of a single rod, thus avoiding the necessity of centering the instrument 